\title{
Cleaning effectiveness of a nickel-titanium ultrasonic tip in ultrasonically activated irrigation: a SEM study
}

Carlos Roberto Emerenciano BUENO'(a)

Marina Tolomei Sandoval CURY(a)

Ana Maria Veiga VASQUES(a)

Jimena Lama SARMIENTO(a)

Juliana Quintino TRIZZI(a)

Rogério Castilho JACINTO(a) iD

Gustavo SIVIERI-ARAUJO(a) (iD

Eloi DEZAN JÚNIOR(a)

(a) Universidade Estadual Paulista- UNESP, Araçatuba School of Dentistry, Department of Endodontics, Araçatuba, SP, Brazil.

Declaration of Interests: The authors certify that they have no commercial or associative interest that represents a conflict of interest in connection with the manuscript.

Corresponding Author:

Eloi Dezan Junior

E-mail: dezan@foa.unesp.br

hitps://doi.org/10.1590/1807-3107bor-2019.vol33.0017

Submitted: July 17, 2018

Accepted for publication: November 26, 2018

Last revision: January 28, 2019
Abstract: In endodontic treatment, regardless of the instrumentation technique, the presence of a smear layer covering contaminated dentin walls is always a concern. Thus, irrigation plays an essential role in reducing bacterial load. To enhance irrigation effectiveness, different ultrasonic activation methods and the use of different tips have been studied. This study assessed the cleaning capacity of the novel NiTi ultrasonic tip for smear layer removal using ultrasonically activated irrigation (UAI) with passive or continuous ultrasonic irrigation (PUI or CUI, respectively), compared with conventional irrigation. Forty-five single-rooted human mandibular premolars were decoronated to a standardized length of $16 \mathrm{~mm}$. Instrumentation was performed using the Genius system up to size 50.04 and irrigated with $3 \% \mathrm{NaOCl}$. The specimens were divided into three groups $(n=15)$ according to the final irrigation activation technique: conventional irrigation (CI), as control group; PUI; and CUI, following the manufacturer's protocol. The samples were longitudinally cleaved and analyzed under a scanning electron microscope for smear layer removal according to a cleanliness score for the cervical, middle, and apical thirds. Data were evaluated by means of the Kruskal-Wallis and Tukey's tests, with a 5\% level of significance. UAI enhanced cleaning compared to conventional irrigation, mainly at the apical third. CUI showed the best results, with statistically significant lower scores than PUI and CI $(p<0.05)$. Final irrigant activation with the NiTi tip showed better cleaning capacity than conventional irrigation. In addition, CUI resulted in better smear layer removal than PUI.

Keywords: Endodontics; Instrumentation; Dental Pulp Cavity.

\section{Introduction}

Root canal instrumentation produces a smear layer, consisting of organic and inorganic material, mainly formed by dentin, pulp tissue remnants, odontoblast processes and, in a contaminated canal, there are also bacteria on dentin walls. ${ }^{1,2}$ The presence of a smear layer hinders penetration of antimicrobial agents and endodontic sealers into dentinal tubules, ${ }^{3,4}$ possibly compromising the sealing between the filling material 
and the root canal wall, which could interfere in treatment success. ${ }^{5}$

Sodium hypochlorite $(\mathrm{NaOCl})$ is a widely used irrigant for root canal disinfection but, when used alone, it is ineffective in smear layer removal. ${ }^{6,7}$ The addition of $17 \%$ ethylenediaminetetraacetic acid (EDTA) to the irrigation protocol, alternating with $\mathrm{NaOCl}$, has been recommended for increasing the effectiveness in smear layer removal.,8

Therefore, irrigation plays an essential role in the removal of pulp tissue, debris, and microorganisms. ${ }^{9,10}$ In the conventional irrigation technique, the needle tip should be 1-2 $\mathrm{mm}$ from the working length $(\mathrm{WL}) ;{ }^{11,12}$ nonetheless, the cleaning of the apical region remains uncertain without the assistance of agitation techniques.

To increase the effectiveness and dynamics of these solutions, different irrigation protocols have been investigated in association with ultrasonically activated irrigation (UAI). ${ }^{13,14}$

Passive ultrasonic irrigation (PUI) was described by Weller et al. ${ }^{15}$ The protocol is based on passive insertion of a metal tip/file attached to an ultrasonic device oscillating at a frequency of $30 \mathrm{kHz}$ into the canal filled with irrigant. ${ }^{15,16}$ After activation, the instrument is surrounded by acoustic streaming, agitating the solution and enhancing debris removal from the apical region, dissociating the bacterial biofilm. ${ }^{17,18}$

Another ultrasonic protocol was proposed by Gutarts et al. ${ }^{19}$ The ultrasonic tip is placed in the canal and the $\mathrm{NaOCl}$ keeps flowing, enabling the irrigant to be continually replaced, providing an uninterrupted supply of nascent chlorine for organic tissue dissolution. ${ }^{6,19}$ This continuous ultrasonic irrigation (CUI) does not require irrigant replacement between ultrasonic file activations ${ }^{20}$ and has demonstrated a significantly greater penetration of irrigant solution when used as a final rinse. ${ }^{14}$

A recent systematic review of activation of irrigants with ultrasonic agitation was conducted by Nagendrababu et al., ${ }^{21}$ emphasizing the use of the term UAI to encompass all ultrasonic activation techniques, whether they are passive or continuous.

The 23-mm nickel-titanium (NiTi) ultrasonic tips $\left(\right.$ NiTiSonic $^{\circledR}$, Ultradent Products Inc, South Jordan,
Utah), recently put on the market, present a 20.02 tip made of NiTi, which, according to the manufacturer, can be used all the way along the working length, even in curved canals. This ultrasonic tip releases irrigant from its base, allowing it to flow to the tip.

Therefore, the aim of this study was to evaluate the ex vivo cleaning effectiveness of the new NiTi ultrasonic tip, comparing the PUI and CUI protocols with conventional syringe irrigation. The null hypothesis was that there would be no difference in cleaning effectiveness of NiTi tips between UAI and conventional irrigation.

\section{Methodology}

\section{Root canal preparation}

Forty-five single-rooted human mandibular premolars with single straight canals and fully formed roots, free from caries, cracks, endodontic treatments, restorations, and curvatures less than $30^{\circ}$, according to Schneider's classification, ${ }^{22}$ were selected from donations made from a dental clinic. Mesiodistal and buccolingual radiographs were taken to confirm a single straight canal and canal space, excluding calcified root canals. The root lengths were standardized to $16 \mathrm{~mm}$ by decoronation, using a high-speed, water-cooled diamond disc. ${ }^{14}$ The tooth length was obtained by introducing \#10 K-file (Dentsply Maillefer, Ballaigues, Switzerland) into the canal to the point of displaying its tip at the apical foramen. The WL was obtained by subtracting $1 \mathrm{~mm}$ from the tooth length. To simulate clinical conditions, the apical region of each root was sealed with a layer of OpalDam Green gingival barrier (Ultradent Products Inc, South Jordan, USA), avoiding extravasation of the irrigating solutions. ${ }^{23}$ To prevent the gingival barrier from entering the canal, a \#10 K-file was inserted before the layer was applied.

Specimens were randomly divided into control group (conventional irrigation) and two experimental groups, PUI and CUI ( $\mathrm{n}=15)$. Root canal instrumentation was performed by the same operator, an endodontic specialist, with Genius reciprocating system (Ultradent Products Inc, South Jordan, USA), according to the manufacturer's 
instructions. After cervical instrumentation with orifice shaper 30.08 , the canals were prepared with a shaping instrument 25.04 , followed by an apical finishing file 50.04, until the working length was reached. Before cervical preparation with the orifice shaper, the canals were rinsed with $1 \mathrm{~mL}$ of $3 \%$ $\mathrm{NaOCl}$ (ChlorCid, Ultradent Products Inc, South Jordan, USA). At each file change (25.04 and 50.04), the canals were irrigated with $2 \mathrm{~mL}$ of $3 \% \mathrm{NaOCl}$ by using a 5-mL syringe and 31-gauge double-side port NaviTip (Ultradent Products Inc, South Jordan, USA) calibrated to stop $-2 \mathrm{~mm}$ from the $\mathrm{WL}$, totalizing $5 \mathrm{~mL}$ per sample during instrumentation before the final irrigation protocol. Ultrawave XS LED piezoelectric ultrasonic device (Ultradent Products Inc, South Jordan, Utah) was used, promoting the CUI protocol by changing the water supply for the specific $\mathrm{NaOCl}$ bottle and the specific 18\% EDTA (Ultradent Products Inc, South Jordan, USA). For PUI and CUI, the noncutting NiTi ultrasonic tip \#20.02 (Figure 1) (Ultradent Products Inc, South Jordan, USA) was used all the way along the working length. Simultaneously, suction was accomplished by using a plastic cannula. Apical patency was maintained at each change of instrument by inserting \#10 K-file up to the apical foramen. The groups were divided according to the final irrigation protocol.

\section{Control group}

After insertion of the last instrument, conventional irrigation with $5 \mathrm{~mL}$ of $3 \% \mathrm{NaOCl}$ was performed using positive pressure irrigation. The canal was then washed and filled with 18\% EDTA for 3 minutes, without agitation, totaling $5 \mathrm{~mL}$; the $18 \%$ EDTA was washed out with $5 \mathrm{~mL}$ of $3 \% \mathrm{NaOCl}$. The solutions were delivered with a 31-gauge double-side port NaviTip (Ultradent Products Inc, South Jordan, USA).

\section{PUI Group}

After insertion of the last instrument, the ultrasonic device was set to power \#4, as recommended by the manufacturer, and the PUI protocol was followed according to van der Sluis et al. ${ }^{18}$ The canal was rinsed and filled with $1 \mathrm{~mL}$ of $3 \% \mathrm{NaOCl}$. The ultrasonic NiTi tip was placed $1.0 \mathrm{~mm}$ short

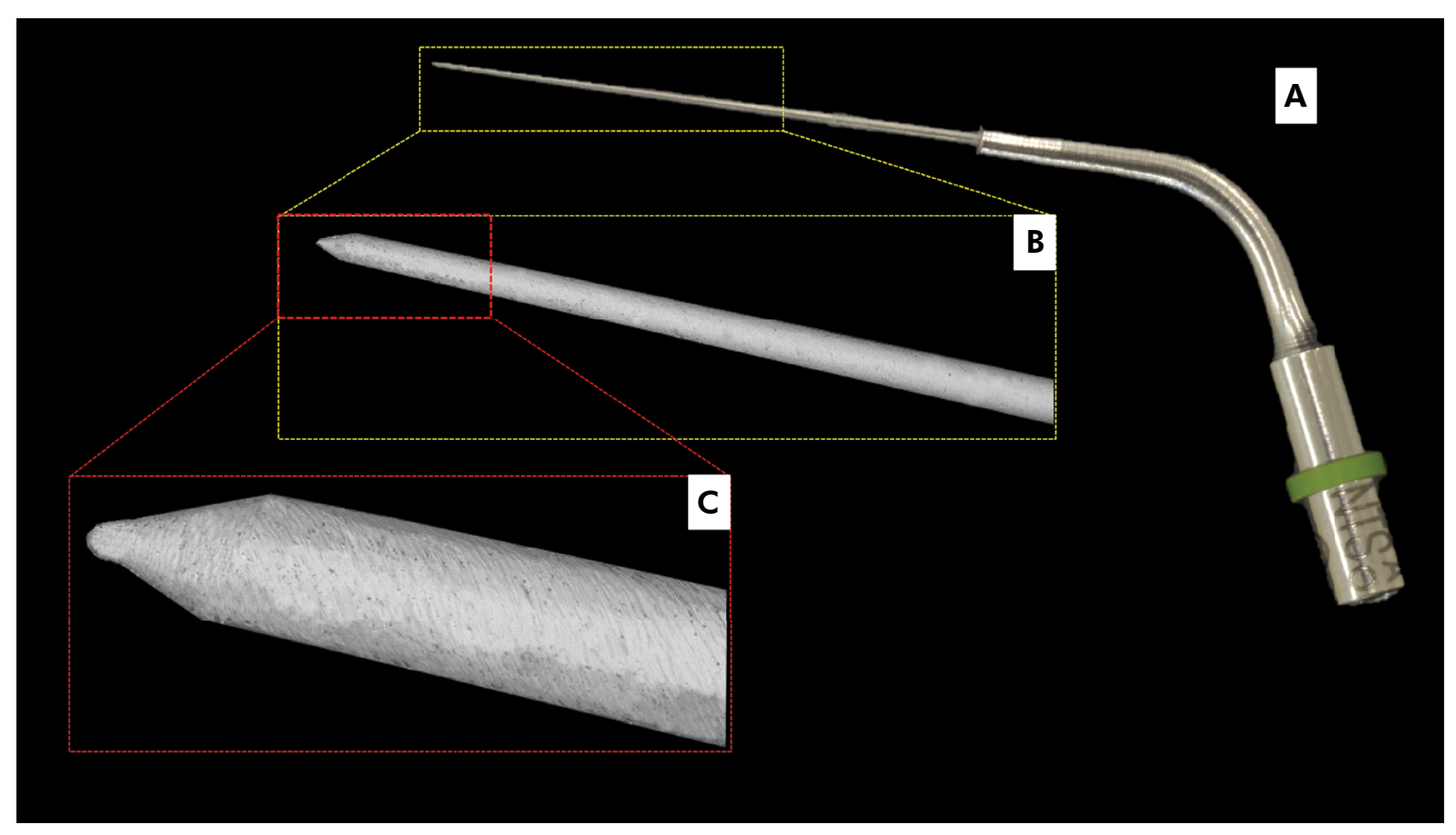

Figure 1. The ultrasonic nickel-titanium tip NiTiSonic ${ }^{\circledR}(\mathrm{A})$; SEM images at 30x magnification (B) and at 150x (C), evidencing the smooth surface and the noncutting tip. 
of the WL and first activated with $\mathrm{NaOCl}$ with three cycles of 20 seconds with $2 \mathrm{~mL}$ of irrigant replacement before each cycle; Then, the canal was rinsed and filled with $1 \mathrm{~mL}$ of $18 \%$ EDTA and the activation protocol was repeated with $2 \mathrm{~mL}$ of solution replacement before each cycle. Lastly, a final agitation with $3 \% \mathrm{NaOCl}$ was repeated, totaling $5 \mathrm{~mL}$ of irrigant during each activation.

\section{CUI Group}

After insertion of the last instrument, the water supply in the ultrasonic device was replaced with the 3\% $\mathrm{NaOCl}$ bottle and set to power \#4, as recommended by the manufacturer. The ultrasonic device was adjusted to release $5 \mathrm{~mL}$ for 30 seconds of activation, and CUI was performed for 30 seconds, with the tip inserted $1 \mathrm{~mm}$ from the WL. Then, the $3 \% \mathrm{NaOCl}$ supply bottle was replaced with the $18 \%$ EDTA bottle, adjusted to release $5 \mathrm{~mL}$ for 30 seconds, and another activation was performed for 30 seconds. The $3 \% \mathrm{NaOCl}$ bottle was reinserted for a final CUI of $5 \mathrm{~mL}$ for 30 seconds, totaling $5 \mathrm{~mL}$ of irrigant during each activation.

At the end of all procedures, all canals were irrigated with $5 \mathrm{~mL}$ of distilled water to remove possible salt residues from the irrigation solutions, ${ }^{23}$ aspirated, and dried with absorbent paper points.

\section{Specimen preparation}

A low-vacuum environmental scanning electron microscope - ESEM (Tabletop Microscope TM3030, Hitachi, Japan) was used to evaluate endodontic smear layer removal from the dentin walls, avoiding the gold coating requirement, which could hinder the analysis. A gutta-percha cone with the same size of the last instrument (Genius gutta percha 50.04, Ultradent Products Inc, South Jordan, USA) was introduced into the canal. ${ }^{23,24}$ In order to facilitate the fractures into halves, longitudinal grooves were made on the buccal and lingual external surfaces of each tooth by using double-sided diamond discs $(22 \mathrm{~mm}$ in diameter and $0.1 \mathrm{~mm}$ in thickness), operated at low speed, and until the presence of the pink gutta-percha cone was seen, avoiding accidental contamination and invasion of the canal by cutting debris. ${ }^{24}$
After the teeth were cleaved with the aid of a chisel, one out of the two halves was selected for evaluation by SEM. Three external markings were made on this half with a fine-tip pen on the external root surface, perpendicularly to the long axis, to divide it into cervical, middle, and apical thirds of the same length. After locating the markings on the canals, the most well-defined area was chosen at a magnification of 50x.

The images were obtained at 500x using a software (TM3030 Hitachi software) and were used to evaluate smear layer removal.

\section{SEM evaluation}

Cleanliness was evaluated according to a 5-score index system, previously used ${ }^{23}$ and codified by Hulsmann et al., ${ }^{25}$ which assesses the presence, quantity, and distribution of the smear layer as follows: score 1, smear layer is completely absent; most tubules are patent and debris-free; score 2, smear layer covering $>25 \%$ of the canal wall and dentinal tubules; score 3 , smear layer evident in $25 \%-50 \%$ of the canal surface and tubules; score 4, smear layer evident in $50 \%-75 \%$ of the canal surface and tubules; and score 5, smear layer covering $75 \%-100 \%$ of the canal surface and tubules.

\section{Statistical evaluation}

The images were blindly evaluated by two observers after a calibration exercise. The kappa test was used to verify intra- and interexaminer reproducibility, in order to validate the subjective findings. The Kruskal-Wallis test was used to compare the results obtained by the scores for cleansing efficacy. Tukey's test was used for pairwise multiple comparison. All statistical calculations were performed using the SigmaPlot Software (version 12.0), with a level of significance of $5 \%$.

\section{Results}

Kappa values of 0.90 and above were obtained, demonstrating excellent intra- and interexaminer agreement for the scores. In the SEM analysis, cleanliness was evaluated by scores for all samples 
Table. Percentage of samples in each group categorized according to the 1-5 smear layer score and the median at the three analyzed canal thirds.

\begin{tabular}{|c|c|c|c|c|c|c|}
\hline \multirow{2}{*}{$\begin{array}{l}\text { Variable } \\
\text { Cervical }\end{array}$} & \multicolumn{5}{|c|}{ Score (\%) } & \multirow[t]{2}{*}{ Median } \\
\hline & 1 & 2 & 3 & 4 & 5 & \\
\hline Control & 50 & 40 & 10 & 0 & 0 & 1 \\
\hline PUI & 60 & 30 & 10 & 0 & 0 & 1 \\
\hline CUI & $100 *$ & 0 & 0 & 0 & 0 & 1 \\
\hline \multicolumn{7}{|l|}{ Middle } \\
\hline Control & 10 & 30 & 25 & 25 & 10 & 2 \\
\hline PUI & 45 & 25 & 10 & 10 & 10 & 1 \\
\hline CUI & 75 & 25 & 0 & 0 & 0 & 1 \\
\hline \multicolumn{7}{|l|}{ Apical } \\
\hline Control & 10 & 20 & 10 & 35 & 25 & 4 \\
\hline PUI & 10 & 45 & 10 & 30 & 5 & 2 \\
\hline CUI & $60^{*}$ & 30 & 0 & 10 & 0 & 1 \\
\hline
\end{tabular}

*Statistical difference.

$(n=15)$, and the results for the various groups are reported in Table as median score.

All groups achieved median score 1 in the cervical area. The control group had the highest scores for the middle (score 2) and apical (score 4) thirds (Table). Although the PUI group had lower smear scores than the control group, there was no statistical difference between the two groups $(\mathrm{p}>0.05)$. The CUI group showed the lowest scores, achieving median 1 at all thirds (Table 1), with statistical difference from both control and PUI groups $(p<0.05)$. There was also a statistical difference between cleanliness at the apical and cervical thirds $(p<0.05)$ and between the middle and cervical thirds $(p<0.05)$. A representative sample from each group is shown in Figure 2.

\section{Discussion}

The present study evaluated the cleaning effectiveness of the new NiTi ultrasonic tips in extracted mandibular premolars from the apical to the cervical thirds. Based on the results, the null hypothesis was rejected because the NiTi ultrasonic tip enhanced smear layer removal during the final irrigation in both UAI protocols. The premolars used had a closed-end canal, to simulate in vivo conditions, in which there is possible gas entrapment inside the root canal and the foramen is sealed by the periodontal ligament and embedded in alveolar bone. ${ }^{26}$

According to a previous report, ${ }^{27}$ the minimum instrumentation size needed for penetration of irrigants into the apical third of the root canal is \#30; however, enlarging the canals to sizes over \#40 is recommended to achieve better cleaning. ${ }^{28,29}$ In order to standardize instrumentation, the protocol was the same for all three groups (CI, PUI, and CUI). The apical third was initially instrumented with a reciprocating file \#25.04 and extended to a \#50.04, in order to allow for adequate penetration of irrigants, since larger canals permit better flow of solutions. . $^{30,31}$

In the literature, there is no consensus about the efficiency of PUI in smear layer removal over conventional irrigation. Previous studies have reported that PUI enhanced canal cleaning, ${ }^{23,32}$ but other studies have shown no difference between those methods. ${ }^{24,33}$ It is important to observe that the PUI protocol used in those studies was different from the one used in the present research as the instrumentation protocol.

PUI followed van der Sluis protocol, according to which three agitation cycles of 20 seconds and replacement of the irrigant solution promote better cleaning, indicating the presence of a cumulative effect. ${ }^{18}$ The efficacy of a three-step protocol with renewal of the irrigants has also been recently 


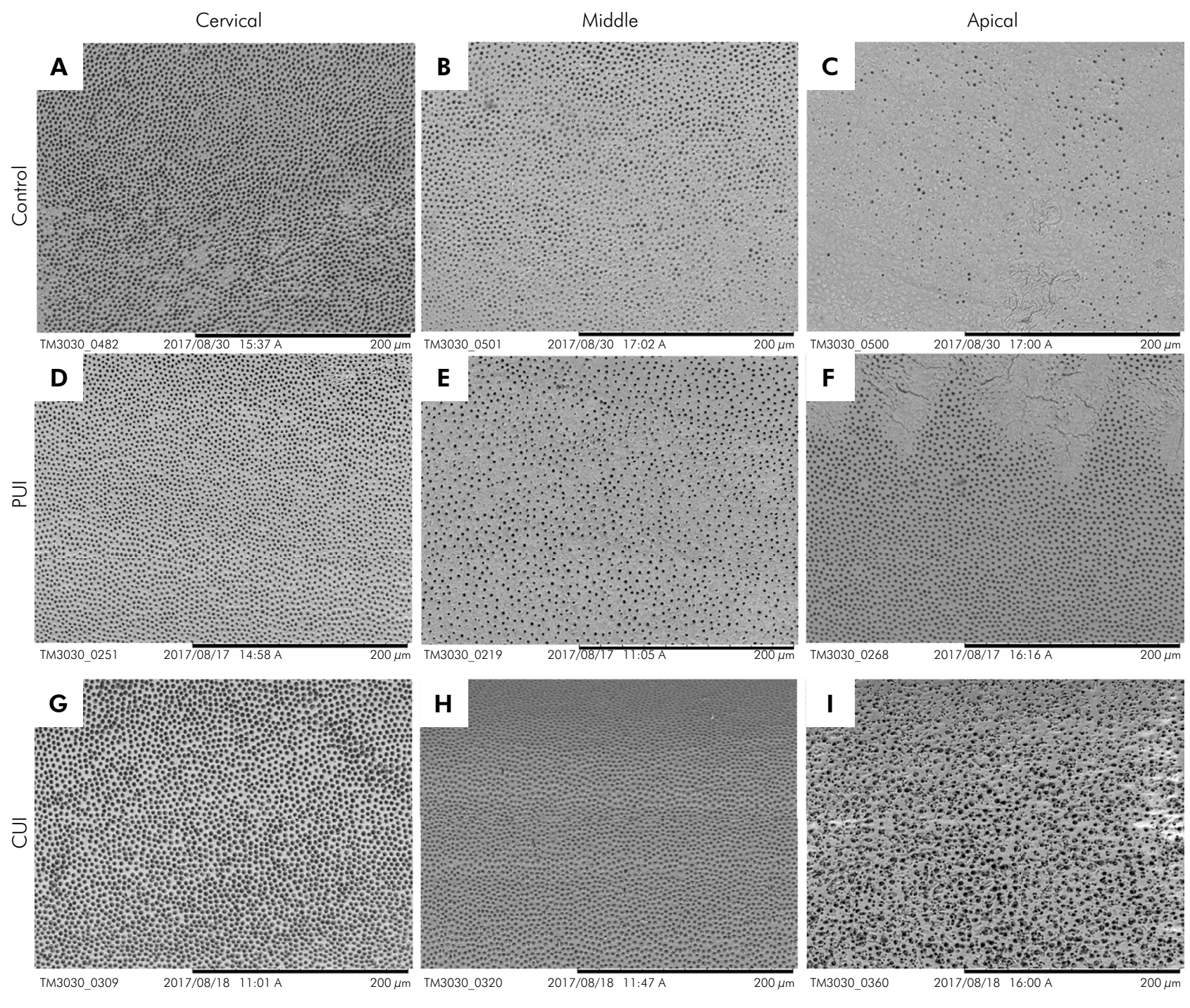

Figure 2. SEM images (500x) of representative samples from the apical, middle, and coronal thirds, illustrating the different irrigant activation techniques. Conventional irrigation (control) group (A-C) showing a clean wall with few smear plugs (arrows) at the coronal third, less open tubules with more smear layer at the middle third, and a thicker smear layer with few open tubules at the apical third, with smear layer evident in 50\%-75\% of the canal surface and tubules. PUI group (D-F) showing a clean wall at the coronal third, less open tubules with more smear layer plugs at the middle third, and a smear layer covering $>25 \%$ of the canal wall and dentinal tubules at the apical third; CUI group (G-I) showing a highly clean canal surface with open dentinal tubules at the coronal, middle, and apical thirds, where most tubules are open and debris-free.

confirmed by Bao et al., ${ }^{34}$ with PUI showing a better cleaning effect than that of conventional needle irrigation. Our results showed an efficient cleaning when this protocol was used, corroborating previous findings. ${ }^{34,35}$ These results might be ascribed to the acoustic microstreaming produced along the instrument by the ultrasonic device, leading to formation of irrigating jets, directed towards the root canal wall. . $^{3,37,38}$
CUI showed the best results regarding cleaning effectiveness. This is in accordance with previous findings reporting that CUI used as a final rinse significantly increases the penetration of the irrigating solution. ${ }^{14}$ Ultrawave XS allows connecting bottles containing EDTA or $\mathrm{NaOCl}$ directly to the ultrasonic device and using the irrigant immediately for PUI or CUI. In addition, it permits a final flush with water, which cleans the equipment internally, preventing 
any damage to it. The EDTA concentration that is commercially available with Ultradent ${ }^{\circledR}$ bottles is $18 \%$. This method allows the continuous replenishment of the solution and its activation by the ultrasonically energized tip, which may explain our results. The release of the irrigant in CUI was set to $5 \mathrm{~mL}$ in 30 seconds, using $5 \mathrm{~mL}$ as standard for all irrigating protocols. Therefore, to adopt the manufacturer's protocol for the NiTi tip, 18\% EDTA was used in the ultrasonic protocol and in the conventional positive pressure irrigation group.

A study concerning dentin erosion found that $17 \%$ EDTA should not remain in contact with root canal walls for more than 1 minute. ${ }^{39}$ However, Mancini et al. ${ }^{23}$ reported that $17 \%$ EDTA for 1 minute was insufficient to completely remove the smear layer from the apical third. In our study, the time for the EDTA protocol was 3 minutes, as used in previous studies. ${ }^{23,24,34}$

Both UAI techniques were compared with each other and also with conventional irrigation. The analyzed data show that both ultrasonic techniques improved cleanliness, but the CUI technique was more effective, as evidenced by the statistical difference. A systematic review has recently demonstrated that UAI provides better root canal disinfection than other irrigation systems. ${ }^{21}$ Our results corroborate those of previous studies, demonstrating that the use of ultrasonic irrigation improves smear layer removal in PUI, ${ }^{13,23,32}$ but mainly in CUI. ${ }^{14}$ Overall, the new NiTi ultrasonic tip enhanced smear layer removal in both UAI techniques, showing better results than the CI technique, as assessed by the cleanliness score.

\section{Conclusions}

Despite the limitations of this study, the new NiTi ultrasonic tip seems to improve smear layer removal, promoting better cleaning than conventional irrigation. In addition, the CUI protocol showed better results than PUI. Further studies are necessary to analyze the behavior of this tip along the WL, as far as irrigant extrusion, dentin removal, or its effectiveness in isthmuses, lateral canals, or curved roots are concerned.

\section{Acknowledgments}

The authors thank Dr. Carlos Alberto Spironelli Ramos for his valuable technical assistance. The authors also thank Ultradent Products, Inc. for providing the ultrasonic tips used in this study.

This research was supported by Coordenação de Aperfeiçoamento de Pessoal de Nível Superior (CAPES) - Brazil.

\section{References}

1. McComb D, Smith DC. A preliminary scanning electron microscopic study of root canals after endodontic procedures. J Endod. 1975 Jul;1(7):238-42. https://doi.org/10.1016/S0099-2399(75)80226-3

2. Mader CL, Baumgartner JC, Peters DD. Scanning electron microscopic investigation of the smeared layer on root canal walls. J Endod. 1984 Oct;10(10):477-83. https://doi.org/10.1016/S0099-2399(84)80204-6

3. Goldberg F, Abramovich A. Analysis of the effect of EDTAC on the dentinal walls of the root canal. J Endod. 1977 Mar;3(3):101-5. https://doi.org/10.1016/S0099-2399(77)80203-3

4. Orstavik D, Haapasalo M. Disinfection by endodontic irrigants and dressings of experimentally infected dentinal tubules. Endod Dent Traumatol. 1990 Aug;6(4):142-9. https://doi.org/10.1111/j.1600-9657.1990.tb00409.x

5. Shahravan A, Haghdoost AA, Adl A, Rahimi $H$, Shadifar F. Effect of smear layer on sealing ability of canal obturation: a systematic review and meta-analysis. J Endod. 2007 Feb;33(2):96-105. https://doi.org/10.1016/i.joen.2006.10.007

6. Zehnder M. Root canal irrigants. J Endod. 2006 May;32(5):389-98. https://doi.org/10.1016/i.joen.2005.09.014

7. Peters $O A$, Barbakow $F$. Effects of irrigation on debris and smear layer on canal walls prepared by two rotary techniques: a scanning electron microscopic study. J Endod. 2000 Jan;26(1):6-10. https://doi.org/10.1097/00004770-200001000-00002

8. Economides N, Liolios E, Kolokuris I, Beltes P. Long-term evaluation of the influence of smear layer removal on the sealing ability of different sealers. J Endod. 1999 Feb;25(2):123-5. https://doi.org/10.1016/S0099-2399(99)80010-7 
9. Haapasalo M, Endal U, Zandi H, Coil JM. Eradication of endodontic infection by instrumentation and irrigation solutions. Endod Top. 2005 Aug;10(1):77-102. https://doi.org/10.1111/j.1601-1546.2005.00135.x

10. Guerreiro-Tanomaru JM, Loiola LE, Morgental RD, Leonardo RT, Tanomaru-Filho M. Efficacy of four irrigation needles in cleaning the apical third of root canals. Braz Dent J. 2013;24(1):21-4. https://doi.org/10.1590/0103-6440201302153

11. Helvacıoğlu Kıvanç B, Deniz Arısu H, Yanar NO, Silah HM, İnam R, Görgül G. Apical extrusion of sodium hypochlorite activated with two laser systems and ultrasonics: a spectrophotometric analysis. BMC Oral Health. 2015 Jun;15(1):71. https://doi.org/10.1186/s12903-015-0056-0

12. Uzunoglu E, Görduysus M, Görduysus Ö. A comparison of different irrigation systems and gravitational effect on final extrusion of the irrigant. J Clin Exp Dent. 2015 Apr;7(2):e218-23. https://doi.org/10.4317/iced.52158

13. Lui JN, Kuah HG, Chen NN. Effect of EDTA with and without surfactants or ultrasonics on removal of smear layer. J Endod. 2007 Apr;33(4):472-5. https://doi.org/10.1016/i.joen.2006.12.007

14. Castelo-Baz P, Martín-Biedma B, Cantatore G, Ruíz-Piñón M, Bahillo J, Rivas-Mundiña B, et al. In vitro comparison of passive and continuous ultrasonic irrigation in simulated lateral canals of extracted teeth. J Endod. 2012 May;38(5):688-91. https://doi.org/10.1016/i.joen.2011.12.032

15. Weller RN, Brady JM, Bernier WE. Efficacy of ultrasonic cleaning. J Endod. 1980 Sep;6(9):740-3. https://doi.org/10.1016/S0099-2399(80)80185-3

16. Grischke J, Müller-Heine A, Hülsmann M. The effect of four different irrigation systems in the removal of a root canal sealer. Clin Oral Investig. 2014 Sep;18(7):1845-51. https://doi.org/10.1007/s00784-013-1161-6

17. Beus C, Safavi K, Stratton J, Kaufman B. Comparison of the effect of two endodontic irrigation protocols on the elimination of bacteria from root canal system: a prospective, randomized clinical trial. J Endod. 2012 Nov;38(11):1479-83. https://doi.org/10.1016/i.joen.2012.07.005

18. Sluis LW, Vogels MP, Verhaagen B, Macedo R, Wesselink PR. Study on the influence of refreshment/activation cycles and irrigants on mechanical cleaning efficiency during ultrasonic activation of the irrigant. J Endod. 2010 Apr;36(4):737-40. https://doi.org/10.1016/j.joen.2009.12.004

19. Gutarts R, Nusstein J, Reader A, Beck M. In vivo debridement efficacy of ultrasonic irrigation following hand-rotary instrumentation in human mandibular molars. J Endod. 2005 Mar;31(3):166-70. https://doi.org/10.1097/01.don.0000137651.01496.48

20. Sluis LW, Versluis M, Wu MK, Wesselink PR. Passive ultrasonic irrigation of the root canal: a review of the literature. Int Endod J. 2007 Jun;40(6):415-26. https://doi.org/10.1111/j.1365-2591.2007.01243.x

21. Nagendrababu V, Jayaraman J, Suresh A, Kalyanasundaram S, Neelakantan P. Effectiveness of ultrasonically activated irrigation on root canal disinfection: a systematic review of in vitro studies. Clin Oral Investig. 2018 Mar;22(2):655-70. https://doi.org/10.1007/s00784-018-2345-x

22. Schneider SW. A comparison of canal preparations in straight and curved root canals. Oral Surg Oral Med Oral Pathol. 1971 Aug;32(2):271-5. https://doi.org/10.1016/0030-4220(71)90230-1

23. Mancini M, Cerroni L, lorio L, Armellin E, Conte G, Cianconi L. Smear layer removal and canal cleanliness using different irrigation systems (EndoActivator, EndoVac, and passive ultrasonic irrigation): field emission scanning electron microscopic evaluation in an in vitro study. J Endod. 2013 Nov;39(11):1456-60. https://doi.org/10.1016/i.joen.2013.07.028

24. Schmidt TF, Teixeira CS, Felippe MC, Felippe WT, Pashley DH, Bortoluzzi EA. Effect of Ultrasonic Activation of Irrigants on Smear Layer Removal. J Endod. 2015 Aug;41(8):1359-63. https://doi.org/10.1016/j.joen.2015.03.023

25. Hülsmann M, Rümmelin C, Schäfers F. Root canal cleanliness after preparation with different endodontic handpieces and hand instruments: a comparative SEM investigation. J Endod. 1997 May;23(5):301-6. https://doi.org/10.1016/S0099-2399(97)80410-4

26. Tay FR, Gu LS, Schoeffel GJ, Wimmer C, Susin L, Zhang K, et al. Effect of vapor lock on root canal debridement by using a side-vented needle for positive-pressure irrigant delivery. J Endod. 2010 Apr;36(4):745-50. https://doi.org/10.1016/i.joen.2009.11.022

27. Khademi A, Yazdizadeh M, Feizianfard M. Determination of the minimum instrumentation size for penetration of irrigants to the apical third of root canal systems. J Endod. 2006 May;32(5):417-20. https://doi.org/10.1016/i.joen.2005.11.008

28. Wu MK, Wesselink PR. Efficacy of three techniques in cleaning the apical portion of curved root canals. Oral Surg Oral Med Oral Pathol Oral Radiol Endod. 1995 Apr;79(4):492-6. https://doi.org/10.1016/S1079-2104(05)80134-9

29. Usman N, Baumgartner JC, Marshall JG. Influence of instrument size on root canal debridement. J Endod. 2004 Feb;30(2):110-2. https://doi.org/10.1097/00004770-200402000-00012

30. Khademi A, Saatchi M, Shokouhi MM, Baghaei B. Scanning electron microscopic evaluation of residual smear layer following preparation of curved root canals using hand instrumentation or two engine-driven systems. Iran Endod J. 2015;10(4):236-9.

31. Caron G, Nham K, Bronnec F, Machtou P. Effectiveness of different final irrigant activation protocols on smear layer removal in curved canals. J Endod. 2010 Aug;36(8):1361-6. https://doi.org/10.1016/i.joen.2010.03.037 
32. Leoni GB, Versiani MA, Silva-Sousa YT, Bruniera JF, Pécora JD, Sousa-Neto MD. Ex vivo evaluation of four final irrigation protocols on the removal of hard-tissue debris from the mesial root canal system of mandibular first molars. Int Endod J. 2017 Apr;50(4):398-406. https://doi.org/10.1111/iej.12630

33. Saber SD, Hashem AA. Efficacy of different final irrigation activation techniques on smear layer removal. J Endod. 2011 Sep;37(9):1272-5. https://doi.org/10.1016/i.joen.2011.06.007

34. Bao P, Shen Y, Lin J, Haapasalo M. In Vitro Efficacy of XP-endo finisher with 2 different protocols on biofilm removal from apical root canals. J Endod. 2017 Feb;43(2):321-5. https://doi.org/10.1016/i.joen.2016.09.021

35. Duque JA, Duarte MA, Canali LC, Zancan RF, Vivan RR, Bernardes RA, et al. Comparative effectiveness of new mechanical irrigant agitating devices for debris removal from the canal and isthmus of mesial roots of mandibular molars. J Endod. 2017 Feb;43(2):326-31. https://doi.org/10.1016/j.joen.2016.10.009

36. Jiang LM, Verhaagen B, Versluis M, Langedijk J, Wesselink P, Sluis LW. The influence of the ultrasonic intensity on the cleaning efficacy of passive ultrasonic irrigation. J Endod. 2011 May;37(5):688-92. https://doi.org/10.1016/i.joen.2011.02.004

37. Malki M, Verhaagen B, Jiang LM, Nehme W, Naaman A, Versluis M, et al. Irrigant flow beyond the insertion depth of an ultrasonically oscillating file in straight and curved root canals: visualization and cleaning efficacy. J Endod. 2012 May;38(5):657-61. https://doi.org/10.1016/j.joen.2012.02.001

38. Wagner MH, da Rosa RA, de Figueiredo JA, Duarte MA, Pereira JR, Só MV. Final irrigation protocols may affect intraradicular dentin ultrastructure. Clin Oral Investig. 2017 Sep;21(7):2173-82. https://doi.org/10.1007/s00784-016-2006-x

39. Çalt S, Serper A. Time-dependent effects of EDTA on dentin structures. J Endod. 2002 Jan;28(1):17-9. https://doi.org/10.1097/00004770-200201000-00004 